\title{
A validade da explicação demográfica para a tendência recente do homicídio de homens jovens em quatro regiões metropolitanas brasileiras (2002-2012) ${ }^{1}$
}

\author{
Alex Manetta ${ }^{2}$ \\ José Eustáquio Diniz Alves
}

\begin{abstract}
Resumo: Este artigo revisa a validade da explicação demográfica para as alterações das condições de vida e da tendência do homicídio para a população jovem masculina, aplicada às regiões metropolitanas de Recife, Salvador, Rio de Janeiro e São Paulo (2002-2012). Utiliza-se como método uma análise descritiva-comparativa das tendências das mudanças na estrutura demográfica; nas taxas de desemprego, de ocupação e de inatividade; nas taxas de homicídio e suas inter-relações. Conclui-se que esta explicação não se aplica ao conjunto de RM avaliadas e que o peso relativo de cada variável tende a ser diferente segundo contextos particulares.
\end{abstract}

Palavras-chave: estrutura etária, homicídio, condições de ocupação, juventude, Brasil.

\section{The validity of the demographic explanation for the recent homicide trend of young men in four Brazilian metropolitan regions (2002-2012).}

\begin{abstract}
This article reviews the validity of the demographic explanation for the changes in living conditions and the trend of homicide among the male youth population, applied to the metropolitan areas of Recife, Rio de Janeiro and São

${ }^{1}$ Recebido em 15/01/18 e aprovado em 30/05/18.

${ }^{2}$ Professor-pesquisador afiliado ao Instituto de Ciências Sociais e Humanidades da Universidade Autônoma do Estado de Hidalgo (UAEH) (Pachuca de Soto, Hidalgo, México). E-mail: alexmanetta@hotmail.com

${ }^{3}$ Professor titular e pesquisador afiliado à Escola Nacional de Ciências Estatísticas (ENCE) do Instituto Brasileiro de Geografia e Estatística (IBGE) (Rio de Janeiro, Rio de Janeiro, Brasil). E-mail: jed_alves@yahoo.com.br
\end{abstract}


Paulo (2002-2012). As method is used a descriptive-comparative analysis of trends in changes in demographic structure; unemployment, occupancy and inactivity rates; in homicide rates and their interrelationships. We conclude that this explanation does not apply to the set of RM evaluated and that the relative weight of each variable tends to be different according to particular contexts.

Keywords: age structure, homicide, conditions of occupation, youth, Brazil.

\section{La validez de la explicación demográfica para la tendencia reciente del homicidio de hombres jóvenes en cuatro regiones metropolitanas brasileñas (2002-2012).}

Resumen: Este artículo revisa la validez de la explicación demográfica para las alteraciones de las condiciones de vida y de la tendencia del homicidio de la población joven masculina, aplicada a las regiones metropolitanas de Recife, Salvador, Río de Janeiro y São Paulo (2002-2012). Se utiliza un análisis descriptivo-comparativo de los cambios en la estructura demográfica; tasas de desempleo, de ocupación y de inactividad laboral; en las tasas de homicidio y sus interrelaciones. Se concluye que la explicación no se aplica al conjunto de RM evaluadas y que el peso relativo de cada variable tiende a ser diferente según contextos particulares.

Palabras clave: estructura de edad, homicidio, condiciones de ocupación, juventud, Brasil.

\section{Introdução ${ }^{4}$}

O Brasil se desenvolveu em um sistema no qual o uso da violência é um recurso frequentemente adotado como forma imediata de resolução de conflitos, representando um fator constitutivo da própria sociedade brasileira (VELHO, 2000). As primeiras grandes vítimas desse processo foram os indígenas, população que declinou de um número em torno de dois e meio milhões no ano de 1500 para cerca de oitocentos mil no ano de 1819 (LIVI-BACCI, 2002).

4 Os autores agradecem ao corpo editorial e aos pareceristas anônimos da Revista Idéias os comentários e as solicitações de mudanças, que muito contribuíram para a qualidade final do texto publicado. 
A violência foi marcante na evolução da sociedade brasileira também através do tráfico de africanos e da escravidão. O Brasil foi o país que mais recebeu escravos provenientes da África, sendo que em meados do século XIX cerca de dois terços da população brasileira era de origem africana (MERRICK; GRAHAM, 1979). Além de todos os tipos de violência a que os africanos e seus descendentes foram submetidos, a escravidão deixou uma herança de exclusão, de preconceito e de desigualdades, dificultando enormemente a construção de uma sociedade justa e pacífica (SOUZA; LIMA, 2006; ADORNO, 2002).

$\mathrm{Na}$ tentativa de elucidar tão diferentes expressões da violência, anteriormente descritas por autores como Domenach (1981), Michaud (1986) e Arendt (1985), Galtung (1990) define violência direta como a perpetração de atos de agressão física dos quais decorrem traumatismos, lesões ou a morte. Refere-se aos atos violentos diretamente exercidos entre pessoas e grupos de pessoas, sendo o homicídio sua expressão extrema. Violência estrutural tem seus significados relacionados à vigência de uma ordem social cujo funcionamento implica oportunidades desiguais para seus membros. Violência cultural faz menção a um sistema de ideias e de crenças que pode ser utilizado para legitimar a perpetração das outras duas categorias. A concepção que move essa distinção categórica e sua articulação através de um triângulo vicioso é bem simples: violência gera violência.

Apesar do fato de que as manifestações da violência, em suas mais variadas formas, sejam constantemente referidas na história da sociedade brasileira (MATTA, 1982), existem evidências de que o panorama recente, desde meados da década de 1980, apresenta novidades, ou seja, características peculiares evidenciadas pelo agravo da violência direta entre homens jovens.

De fato, no Brasil, o crescimento recente das taxas de homicídio afetou particularmente o segmento masculino jovem, tanto nas capitais e regiões metropolitanas quanto no interior do país (WAISELFISZ, 2014), em um contexto no qual predominam os crimes cometidos em locais públicos, entre pessoas que não eram íntimas e nem mesmo conhecidas (ZALUAR, 2007). 
Em termos demográficos os homicídios não só reduzem a esperança de vida e influem na inflexão precoce da razão de sexo da população brasileira (MANETTA; ALVES, 2015), como interferem também na dinâmica familiar, figurando como um grave problema social e de saúde pública (MINAYO, 2005).

A magnitude desse problema, sua disseminação pelo território e seu estabelecimento como um problema crônico, são fatos que justificam o presente estudo, pois, somente através de um entendimento mais complexo e abrangente dessa realidade é que será possível ampliar as possibilidades de formulação estratégica e de gerenciamento de ações voltadas à mitigação desse fenômeno, que há décadas assola a sociedade brasileira.

\section{Problematização}

A persistência das desigualdades sociais (BERCOVICH; DELLASOPPA; ARRIAGA, 1998), da pobreza e do desemprego (OLIVEIRA; PINTO, 2001; HIRATA, 2001), têm sido aspectos avaliados como fatores básicos desencadeadores de elevados índices de criminalidade, constituindo campos altamente propícios ao desenvolvimento da violência juvenil homicida no Brasil. Os resultados de estudos como os de Aidar (2003) e de Ferreira, Vasconcelos e Penna (2008), evidenciam maiores taxas de homicídio juvenil masculino em conjunturas onde a violência estrutural atinge os mais extensos segmentos da população.

Outra linha explicativa, que se entrecruza com a primeira, introduz a análise demográfica como fator relevante, com referência ao processo de transição demográfica, especificamente no que diz respeito às sucessivas alterações na estrutura etária da população. Como efeito de variações nas componentes ${ }^{5}$ básicas da dinâmica da população, especialmente nas tendências da fecundidade, a pirâmide etária brasileira tem passado por estreitamentos e

\footnotetext{
5 As componentes da dinâmica demográfica, estritamente definidas, são: fecundidade, mortalidade e migração (SWANSON; SIEGEL, 1976).
} 
alargamentos bruscos, como resultados do aumento e da posterior diminuição do número de nascimentos em anos subsequentes.

Bercovich e Madeira (1990) denominaram descontinuidades a essas variações no tamanho de coortes sucessivas e onda jovem ao incremento brusco do percentual de jovens na população total. A questão central dessa proposição se encontra na análise das mudanças nas condições de inserção no mercado de trabalho resultantes da pressão de um crescente contingente juvenil (BERCOVICH; MASSÉ, 2004), assim como em suas consequências com relação às possíveis implicações do aumento da competitividade entre jovens no contexto dos conflitos e das tensões sociais, particularmente no que diz respeito à disseminação da criminalidade e do homicídio (BERCOVICH, 2004).

Easterlin (1980) já considerava que o sucesso particular dos membros de uma coorte depende, dentre outros fatores, da quantidade de seus membros. Ou seja, se o volume de jovens em uma sociedade é crescente e a oferta de empregos para essa população se mantém ou diminui, o resultado esperado seria uma tendência à elevação da competição, com reflexos nas taxas de desemprego e no desenvolvimento de situações de mais ampla deterioração social.

Dentro dessa perspectiva, as dificuldades impostas aos jovens em encontrar ocupação laboral adequada foram aspectos considerados relevantes na explicação da elevação das taxas de homicídio no Brasil e no estado de São Paulo durante os anos 1990 (BERCOVICH; MADEIRA, 1990; BERCOVICH; MASSÉ, 2004; BERCOVICH, 2004), quando foram registrados incrementos significativos no percentual da população jovem em um contexto de recessão econômica.

Apesar da consistência empírica da explicação demográfica, persistem controvérsias sobre as causas imediatas do incremento das taxas de homicídio juvenil masculino no Brasil, já que mesmo passado o período caracterizado pela onda jovem essas taxas permanecem elevadas e em uma tendência de crescimento em nível nacional (WAISELFISZ, 2014). 
Feitas essas considerações, explicita-se o objetivo geral desse artigo: revisar a validade recente (2002-2012) da formulação que relaciona o fenômeno da onda-jovem a um processo de agravo nas condições de vida da população juvenil masculina, o que inclui más condições de inserção laboral e a elevação do risco de vitimização por homicídio.

Como objetivo específico propõe-se observar se existe inter-relações entre três distintos fenômenos: as alterações na composição etária da população; a evolução das taxas de emprego, de desemprego e de inatividade e a tendência das taxas de homicídio entre homens jovens, nas RM de Recife, de Salvador, do Rio de Janeiro e de São Paulo (2002-2012).

\section{Materiais e métodos}

A avaliação das alterações na estrutura demográfica (volume absoluto e percentual relativo de homens jovens) foi baseada nas Projeções da População (IBGE, 2013), cuja revisão incorporou parâmetros calculados a partir dos resultados do Censo Demográfico 2010 e informações atualizadas sobre os regimes de fecundidade e de mortalidade no Brasil, disponibilizando informação adequada ao período de referência desse estudo, sendo útil também no cálculo dos indicadores sociais e demográficos apresentados, por sexo e por grupos quinquenais de idade.

O cálculo das taxas de ocupação, de desemprego e de inatividade foi realizado com base nos microdados da Pesquisa Mensal do Emprego (PME nova - IBGE). Do total da população com idades entre 15-19 e 20-24 anos, calculou-se a proporção de pessoas ocupadas (tinha trabalho no período de referência), desempregadas (não ocupados que buscaram trabalho) ou inativas (não ocupados que não buscaram trabalho), de maneira que as três categorias juntas somam 100 (\%) para cada grupo etário. Já o cálculo das taxas de homicídio (homicídios para cada $100 \mathrm{mil}$ pessoas) foi realizado com base nos registros oficiais de óbitos do SIM/MS, em acordo com a décima revisão da Classificação Internacional de Doenças (CID-10), sendo considerados os óbitos registrados nas categorias de X85 a Y09 e Y35-Y36 (2002-2012). 
Através das informações disponibilizadas, foram gerados indicadores que permitiram a realização de uma análise descritivocomparativa, considerando as tendências da dinâmica demográfica, das condições de inserção no mercado de trabalho e das taxas de homicídio em quatro regiões metropolitanas brasileiras (20022012).

Os resultados apresentados fazem referência a jovens do sexo masculino, em uma análise que diferencia dois grupos etários distintos (15-19 e 20-24 anos), dadas as diferenças esperadas em termos de ocupação e inatividade laboral. O conjunto de dados obtido foi objeto das descrições e das análises contidas no Item 1 (Resultados), no Item 2 (Discussão) e no Item 3 (Conclusões), mantendo como referência a análise crítica da validade atual da explicação demográfica para a elevação do homicídio juvenil masculino no contexto de quatro RM brasileiras.

A decisão de trabalhar com as quatro RM selecionadas deuse pelo fato de ser o homicídio juvenil masculino um fenômeno reconhecidamente urbano, que se expressa em sua maior intensidade em zonas metropolitanas. Além disso, as RM objeto desse estudo representam diferentes tendências em termos da evolução das taxas de homicídio e das condições de ocupação laboral, desemprego e inatividade, ainda que em todas elas houve o registro de um decremento absoluto e proporcional da população juvenil masculina, de maneira que esta análise proporciona dados interessantes para uma discussão sobre a relação entre as variáveis de interesse. Outro ponto que deve ser mencionado é que a PME nova (IBGE), é uma fonte que disponibiliza dados adequados para estudos sobre as condições de inserção laboral por sexo e grupos de idade em dez RM brasileiras, cuja cobertura inclui as quatro RM selecionadas e o período de interesse nesse estudo. 


\section{1 - Resultados}

\section{1 - Dinâmica da população juvenil masculina (2002-2012)}

As alterações na composição da população juvenil masculina foram acompanhadas por um decremento geral em seu volume, mais intenso para o grupo de 15-19 anos do que para o grupo dos 20-24 anos, nas RM de Recife, de Salvador e do Rio de Janeiro. Na RM de São Paulo, embora o grupo dos 20-24 anos tenha registrado um leve incremento, seu volume foi amplamente superado pelo decremento do grupo dos 15-19 anos, de modo que a população jovem total (15-24 anos) se reduziu no período (2002-2012) (Gráfico $1)$.

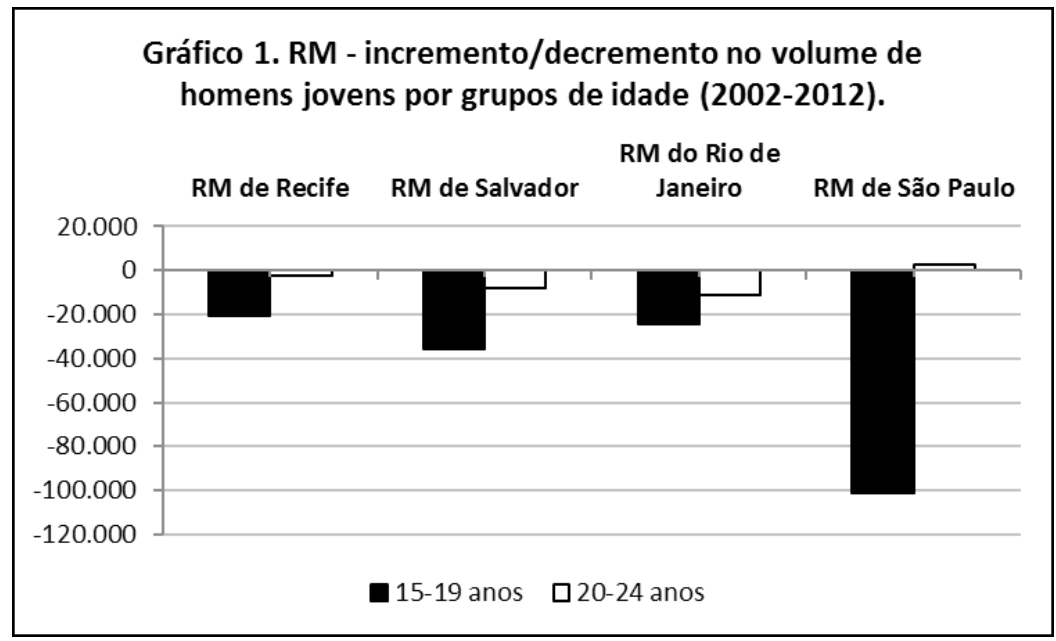

Fonte: elaboração própria com base nas Projeções da População (2013) - IBGE.

As alterações na estrutura etária da população levaram também a uma redução no percentual dos grupos juvenis, com relação à população total masculina, mais intensa para o grupo dos 15-19 do que para o grupo dos 20-24 anos, nas quatro RM observadas (Gráfico 2). 
Os diferenciais da redução proporcional do volume de jovens na população total masculina (2002-2012) são evidentes em todas as quatro RM observadas. Nota-se, entretanto, que a RM de Salvador registrou as maiores variações para ambos grupos observados (15-19 e 20-24 anos). Na sequência das maiores variações relativas aparecem as RM de Recife, de São Paulo (particularmente em relação ao grupo dos 15-19 anos) e do Rio de Janeiro (Gráfico 2).

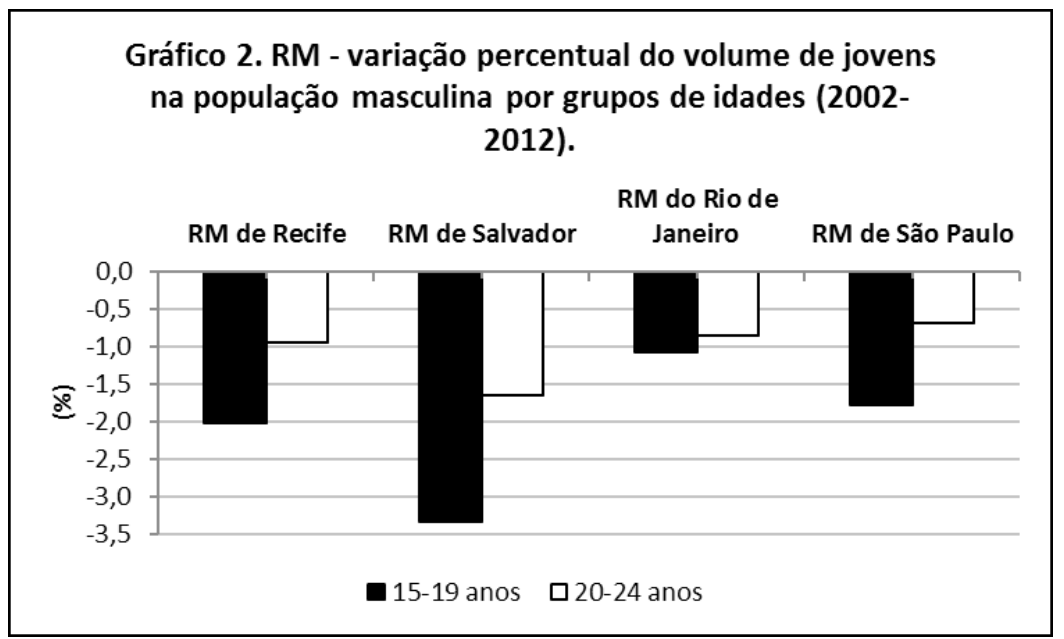

Fonte: elaboração própria com base nas Projeções da População (2013) - IBGE.

Teoricamente, e em acordo com o ponto de vista puramente demográfico, o decremento absoluto e proporcional de homens jovens (2002-2012) tenderia a representar uma redução da pressão na demanda por inserção laboral para os dois grupos avaliados (1519 e 20-24 anos), representando uma oportunidade para a melhoria nos indicadores de ocupação, caracterizando-se como um fator positivo na geração de condições mais amenas de competição e de sobrevivência da população juvenil masculina nas RM avaliadas. 


\section{2 - Ocupação, desemprego e inatividade (2002-2012)}

A análise das taxas de ocupação nas RM de interesse (20022012) salienta em primeiro plano um diferencial por grupo etário (15-19 e 20-24 anos). Essa diferença era já esperada, considerando que o grupo com idades entre 15-19 anos é composto em sua maioria por jovens em idade escolar, motivo pelo qual tende a pressionar menos o mercado de trabalho, com relação ao grupo com idades entre 20-24 anos (Gráficos 3a e 3b).

Em termos de ocupação, são evidentes também as diferenças por RM. A RM de São Paulo se destaca pelas mais elevadas taxas, tanto para o grupo dos 15-19 quanto para o grupo dos 20-24 anos. Em segundo lugar aparece a RM do Rio de Janeiro, de forma mais evidente para o grupo dos 20-24 anos. Em terceiro lugar, se alternando durante o período, aparecem as RM de Recife e de Salvador, para os dois grupos analisados (2002-2012) (Gráficos 3a e $3 b)$.

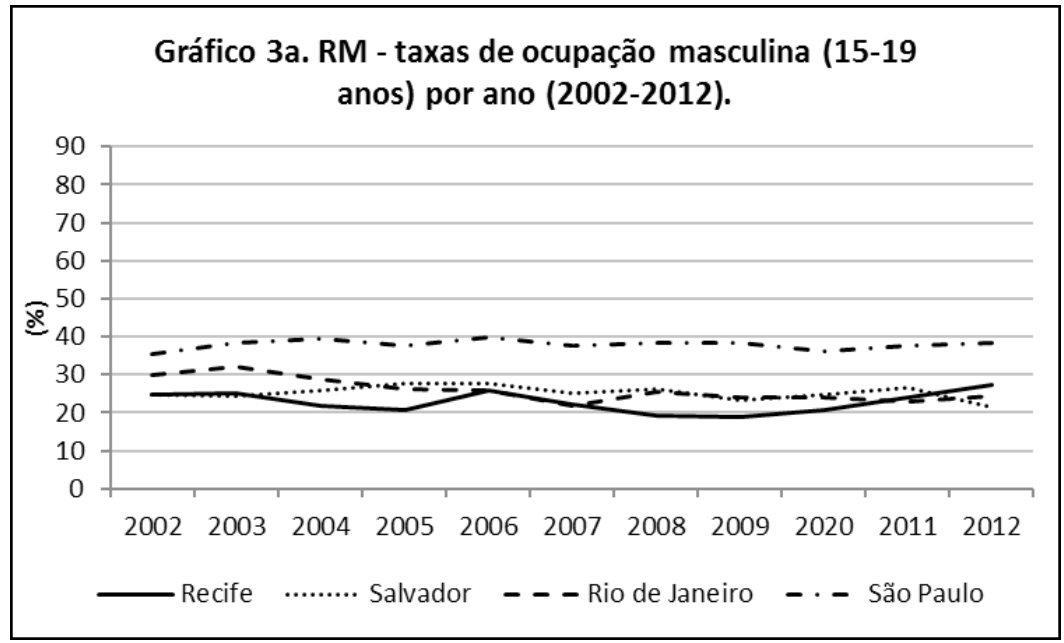

Fonte: elaboração própria com base nos dados da PME (2002-2012), Censo Demográfico (2010) e Projeções da População (2013) - IBGE. 


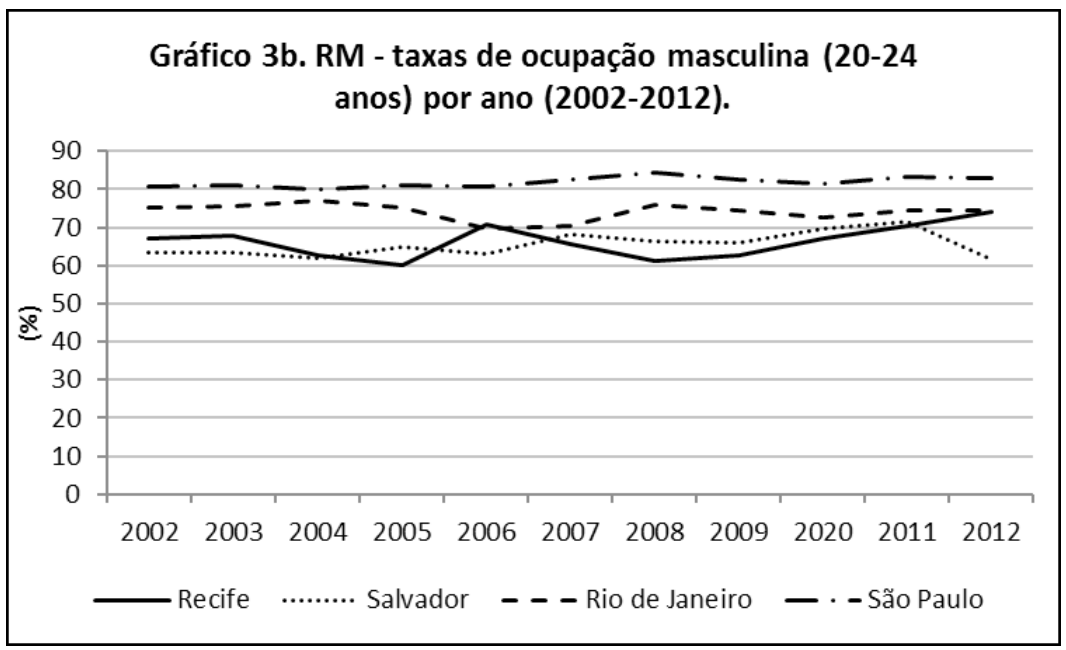

Fonte: elaboração própria com base nos dados da PME (2002-2012), Censo Demográfico (2010) e Projeções da População (2013) - IBGE.

As taxas de ocupação revelam uma relativa estabilidade na RM de São Paulo. Nas RM de Recife, de Salvador e do Rio de Janeiro, as taxas apresentaram maior oscilação, tornando difícil a observação de alguma tendência no período (2002-2012) (Gráficos $3 a$ e $3 b)$.

No entanto, uma análise da variação percentual da ocupação entre o início (2002) e o final (2012) do período, demonstra que na RM de Recife, as taxas de ocupação aumentaram mais de 10\%, para os dois grupos avaliados, resultado que condiz relativamente bem com a tese da onda jovem, já que nessa RM o percentual de população jovem diminuiu para os dois grupos avaliados (20022012) (Gráfico 4).

Na RM de Salvador, onde a variação da população juvenil masculina foi relativamente maior, as taxas de ocupação diminuíram entre o início (2002) e o final (2012) do período, por volta de $13 \%$ e 3\%, para os grupos dos 15-19 e dos 20-24 anos, respectivamente. A redução das taxas de ocupação na RM de Salvador foi maior justamente para o grupo que apresentou maior 
redução em sua representação proporcional (15-19 anos), em um efeito oposto daquele esperando em um contexto de esgotamento da onda jovem (2002-2012) (Gráfico 4).

Na RM do Rio de Janeiro as taxas de ocupação também diminuíram, variando quase $19 \%$ para o grupo dos 15-19 e por volta de $0,5 \%$ para o grupo dos 20-24 anos, reconhecendo-se também um efeito oposto ao esperado em contextos de diminuição percentual e absoluto dos grupos jovens (2002-2012) (Gráfico 4).

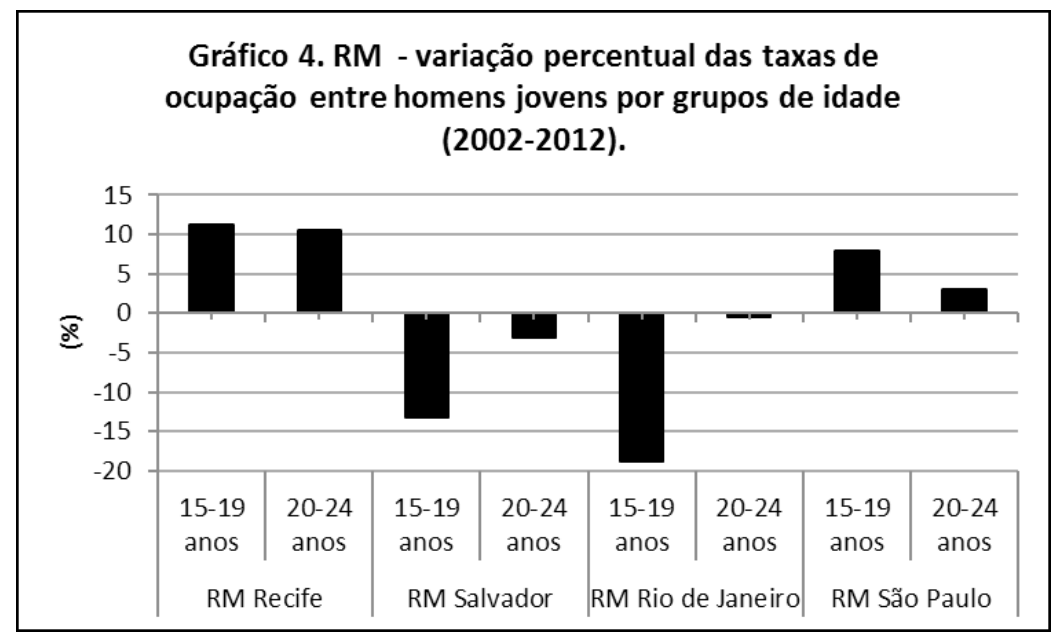

Fonte: elaboração própria com base na PME (2002-2012) e Projeções da População (2013) - IBGE.

Na RM de São Paulo as taxas de ocupação aumentaram no período, sendo que variaram quase $8 \%$ para o grupo dos $15-19$ e por volta de $3 \%$ para o grupo dos 20-24 anos, em uma evolução que em termos gerais se alinha à proposição da onda jovem (Gráfico 4).

Pensando nas relações entre dinâmica demográfica e ocupação, em um primeiro momento, parece evidente que a redução proporcional dos grupos juvenis masculinas pode ter se convertido na melhoria das condições de ocupação laboral nas RM de São Paulo e de Recife, onde as taxas de ocupação aumentaram, mas não nas RM de Salvador e do Rio de Janeiro, onde as taxas de ocupação diminuíram. 
Com relação às taxas de desemprego entre homens jovens é fato que oscilaram bastante, o que pode representar resultados derivados do método de amostra, tornando difícil a apreensão de tendências no período. Entretanto, na RM de Recife as taxas de desemprego foram mais elevadas para o grupo dos 20-24 do que para o grupo dos 15-19 anos durante a maior parte do período, com exceção dos anos 2005 e 2009. Com relação à RM de Salvador, as taxas de desemprego foram mais elevadas para o grupo dos 1519 do que para o dos 20-24 anos, com exceção dos anos de 2002 e 2006 (2002-2012) (Gráficos 5a e 5b).

$\mathrm{Na}$ RM do Rio de Janeiro as taxas de desemprego mantiveram-se mais elevadas para o grupo dos 20-24 do que para o grupo dos 15-19 anos, durante todo o período, com exceção dos anos de 2004 e 2008, quando as taxas dos dois grupos praticamente convergiram. Na RM de São Paulo as taxas de desemprego foram mais elevadas para o grupo dos 15-19 anos durante quase todo o período, com exceção do ano de 2009, quando as taxas dos dois grupos convergiram (2002-2012) (Gráficos 5a e 5b).

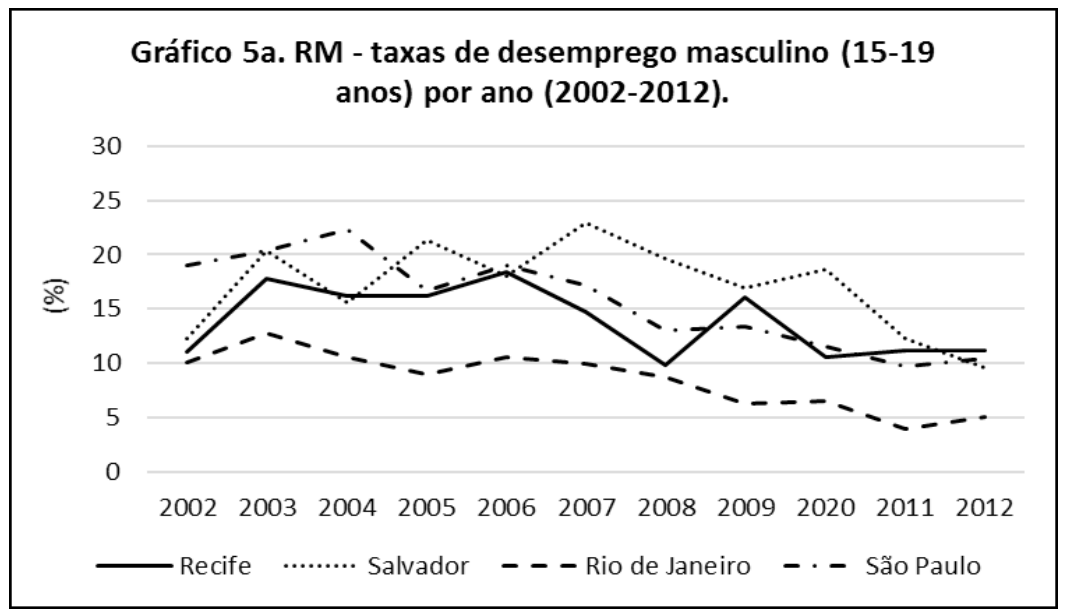

Fonte: elaboração própria com base na PME (2002-2012) e Projeções da População (2013) - IBGE. 


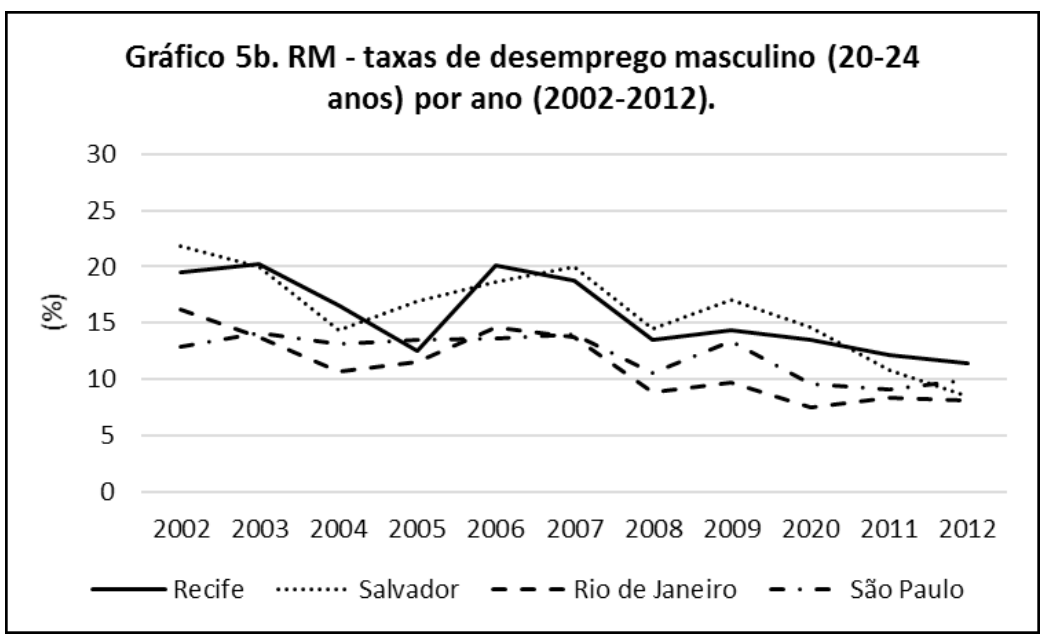

Fonte: elaboração própria com base na PME (2002-2012) e Projeções da População (2013) - IBGE.

A variação percentual das taxas de desemprego entre o início e o final do período (2002-2012) revela variação negativa para os dois grupos (15-19 e 20-24 anos) nas RM de Salvador, do Rio de Janeiro e de São Paulo, sendo que na RM de Recife a variação foi negativa para o grupo dos 20-24 e positiva para o grupo dos 15-19 anos (Gráfico 6). 


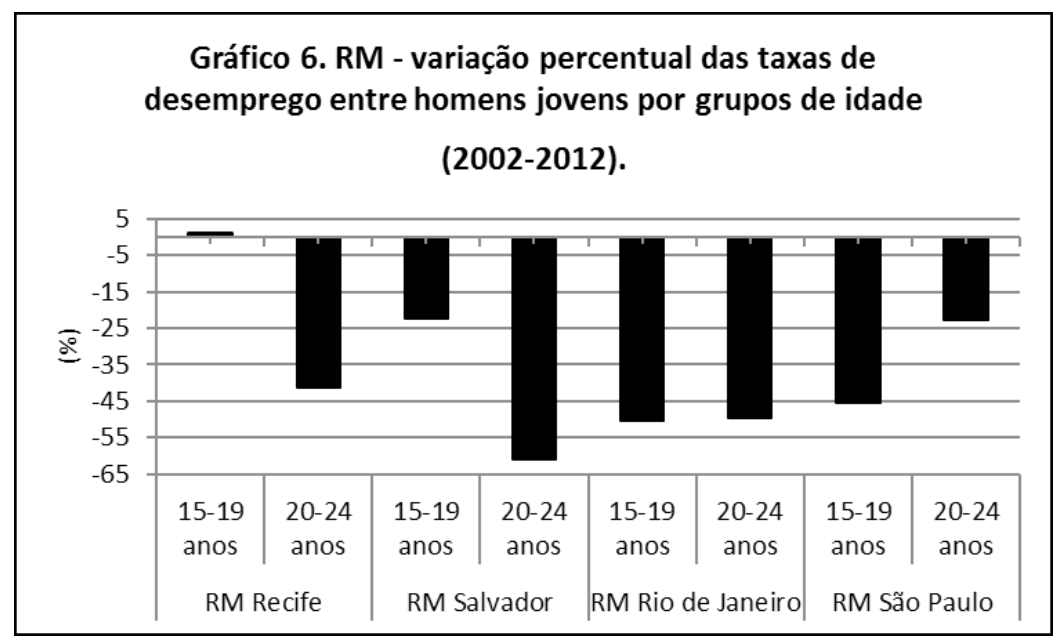

Fonte: elaboração própria com base na PME (2002-2012) e Projeções da População (2013) - IBGE.

O decrescimento nas taxas de desemprego seria um resultado esperado em contextos de aumento nas taxas de ocupação. No entanto, a diminuição do desemprego só foi acompanhada pelo aumento da ocupação nas RM de Recife e de São Paulo. Nas RM de Salvador e do Rio de Janeiro, a diminuição do desemprego foi acompanhada pela elevação da inatividade, conforme se pode observar na sequência da descrição dos dados.

De maneira geral, e conforme o esperado, as taxas de inatividade foram mais elevadas para o grupo dos 15-19 do que para o grupo dos 20-24 anos, nas quatro RM avaliadas, já que fazem referência a um segmento no qual a maior parte de seus membros está em idade escolar. Com relação ao diferencial por RM, a inatividade foi mais elevada nas RM do Rio de Janeiro, de Recife e de Salvador do que na RM de São Paulo, para ambos grupos avaliados (2002-2012) (Gráficos 7a e 7b). 


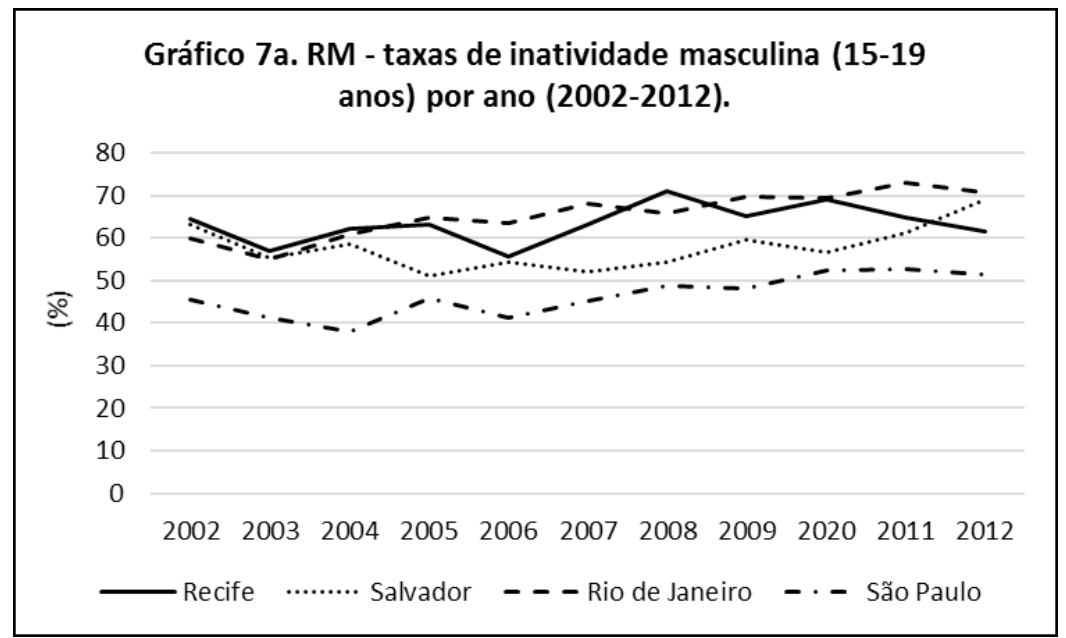

Fonte: elaboração própria com base na PME (2002-2012) e Projeções da População (2013) - IBGE.

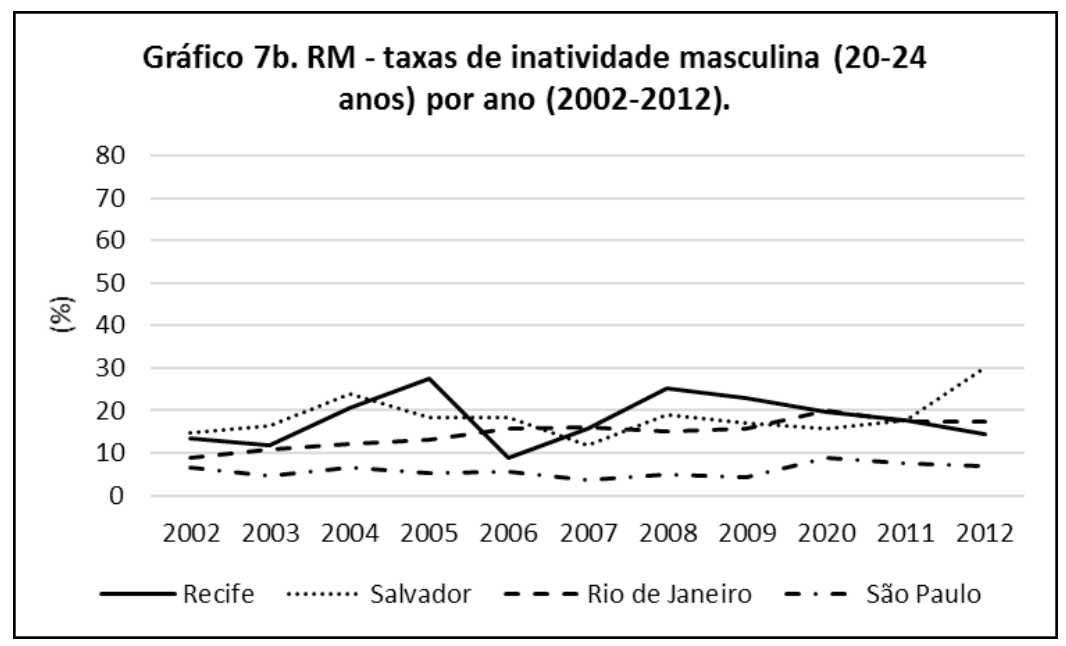

Fonte: elaboração própria com base na PME (2002-2012) e Projeções da População (2013) - IBGE. 
A variação percentual da inatividade entre homens jovens foi positiva para os dois grupos avaliados nas RM de Salvador, do Rio de Janeiro e de São Paulo. Na RM de Recife a variação foi positiva para o grupo dos 20-24 e negativa para o grupo dos 15-19 anos. Esse indicador destaca ainda o elevado aumento percentual das taxas de inatividade entre homens do grupo dos 20-24 anos nas RM de Salvador e do Rio de Janeiro (2002-2012) (Gráfico 8).

Salienta-se que na RM de São Paulo se observaram indicações de que a redução proporcional de jovens na população masculina foi acompanhada pela redução da pressão no mercado de trabalho para os grupos juvenis. É interessante notar que o aumento na ocupação e a diminuição no desemprego foram mais intensos justamente para o grupo dos 15-19 anos, o que mais decresceu no período, tanto em termos absolutos e quanto em termos relativos (Gráfico 8).

De fato, na RM de São Paulo foi registrado um aumento gradual nas taxas de ocupação e diminuição nas taxas de desemprego, com um aumento moderado nas taxas de inatividade (2002-2012). Esse parece ser um resultado conjunto da diminuição da pressão dos grupos jovens no mercado de trabalho e talvez de uma tendência de aumento da matrícula no ensino formal, tanto no ensino médio quanto no ensino superior, provavelmente em uma conjuntura estável de oportunidades de inserção social, no entanto, esse tipo de avaliação não constitui objeto desse trabalho. 


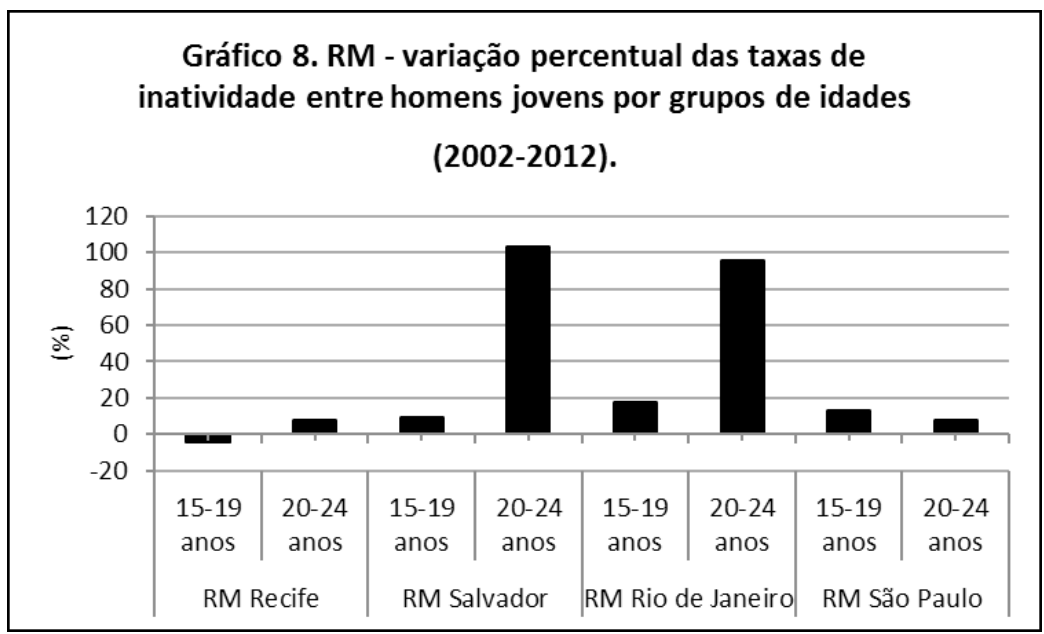

Fonte: elaboração própria com base na PME (2002-2012) e Projeções da População (2013) - IBGE.

Na RM de Recife o comportamento das condições laborais correspondeu parcialmente ao esperado em um contexto de diminuição percentual da população juvenil masculina, já que as taxas de ocupação melhoram para os dois grupos avaliados (1519 e 20-24 anos) e as taxas de desemprego diminuíram somente para o grupo dos 20-24 anos. Entretanto, o aumento das taxas de desemprego para o grupo dos 15-19 anos não ocorreu em função da diminuição da ocupação, mas sim em função de uma diminuição da inatividade, fato que pode estar ligado a uma estrutura social com menos oportunidades de inserção laboral e educacional e que poderia levar muitos jovens com idades entre 15-19 anos à busca por emprego, ao invés da busca por melhor qualificação.

$\mathrm{Na} \mathrm{RM}$ de Salvador, onde a diminuição proporcional dos grupos juvenis foi mais intensa, as taxas de ocupação e de desemprego caíram ao mesmo tempo em que as taxas de inatividade aumentaram. Essa situação foi mais evidente no caso do grupo dos 15-19 anos, justamente aquele que mais decresceu no período. Talvez essa diminuição nas taxas de ocupação e de desemprego, 
com aumento da inatividade, possa estar relacionada à vigência de programas públicos voltados à diminuição do trabalho infantojuvenil e ao aumento nas taxas de matrícula escolar, constituindo-se como indicadores de melhoria no bem-estar social. No entanto, se a elevação dessas taxas está relacionada ao aumento na proporção de jovens que não estudam, não trabalham e tampouco buscam emprego, essa é uma conjuntura bastante preocupante.

Na RM do Rio de Janeiro se observa uma situação semelhante à observada na RM de Salvador, onde caíram as taxas de ocupação e de desemprego e se elevaram as taxas de inatividade, para os dois grupos observados. Porém, diferentemente do observado na RM de Salvador, essa situação se intensificou mais para o grupo dos 20-24 anos.

Do ponto de vista possibilitado pela explicação demográfica, somente na RM de São Paulo é que a diminuição da pressão dos grupos juvenis foi acompanhada pela melhoria dos indicadores de ocupação e de desemprego para os dois grupos avaliados, onde deveria ser esperado como resultado uma diminuição das taxas de homicídio entre homens jovens. Na RM de Recife essa relação pode ser observada especificamente para o grupo dos 20-24 anos. Já nas RM de Salvador e do Rio de Janeiro, onde o volume e o percentual de homens jovens declinaram de maneira mais significativa, as condições laborais não apresentaram indicações claras de melhoria, de maneira que o suposto demográfico não se aplica como regra para o conjunto de RM observadas.

\section{3 - Homicídio juvenil masculino (2002-2012)}

Nas RM de interesse, de forma geral, as taxas de homicídio juvenil masculino mantiveram-se mais elevadas para o grupo dos 20-24 anos, com exceção da RM de Salvador no final do período (2002-2012), quando a taxa do grupo dos 15-19 foi mais elevada (Gráficos 9a e 9b).

Os diferenciais nas tendências de evolução das taxas de homicídio juvenil masculino foram bastante relevantes no período (2002-2012) entre as RM avaliadas. Na RM de Recife, onde foram 
registradas as maiores taxas no início do período (2002-2007), observam-se significativas reduções, chegando ao final do período com taxas menores do que aquelas observadas na RM de Salvador (2008-2012) (Gráficos 9a e 9b).

Na RM de Salvador, onde foram registradas as menores taxas no início do período (2002 e 2003), foi observada uma intensa elevação, chegando ao final do período com as mais elevadas taxas de homicídio juvenil masculino dentre as RM avaliadas (20082012) (Gráfico 9).

Na RM do Rio de Janeiro foi registrada uma tendência decrescente das taxas de homicídio juvenil masculino, mantendose mais elevadas somente com relação aquelas observadas na RM de São Paulo, onde houve também declínio (Gráficos 9a e 9b).

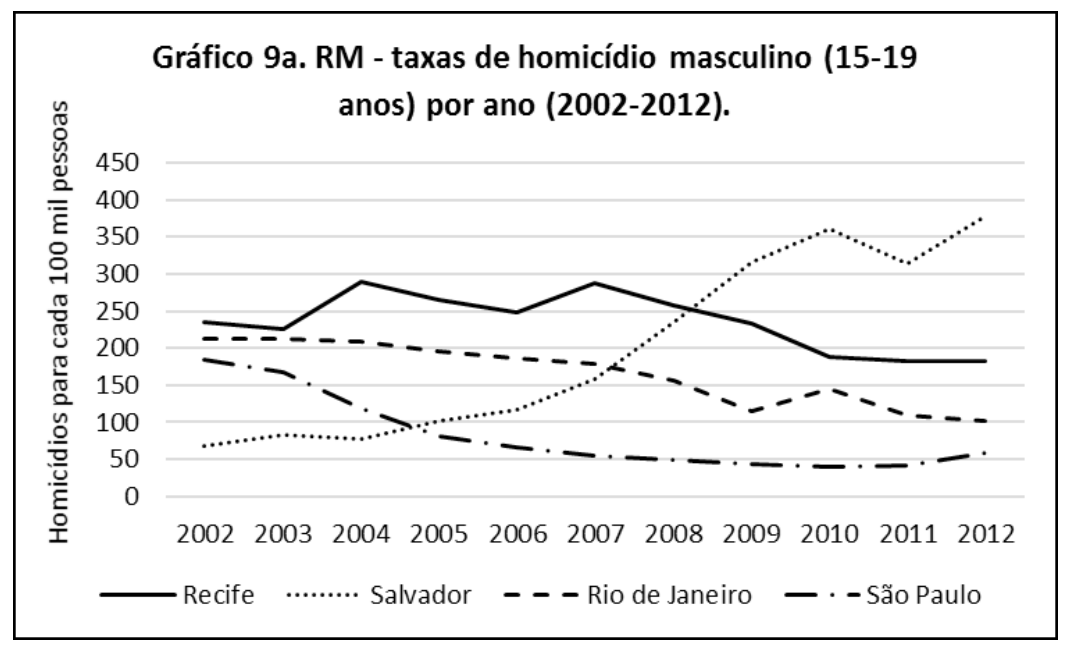

Fonte: elaboração própria com base nos dados do SIM/DATASUS/MS e Projeções da População (2013) - IBGE. 


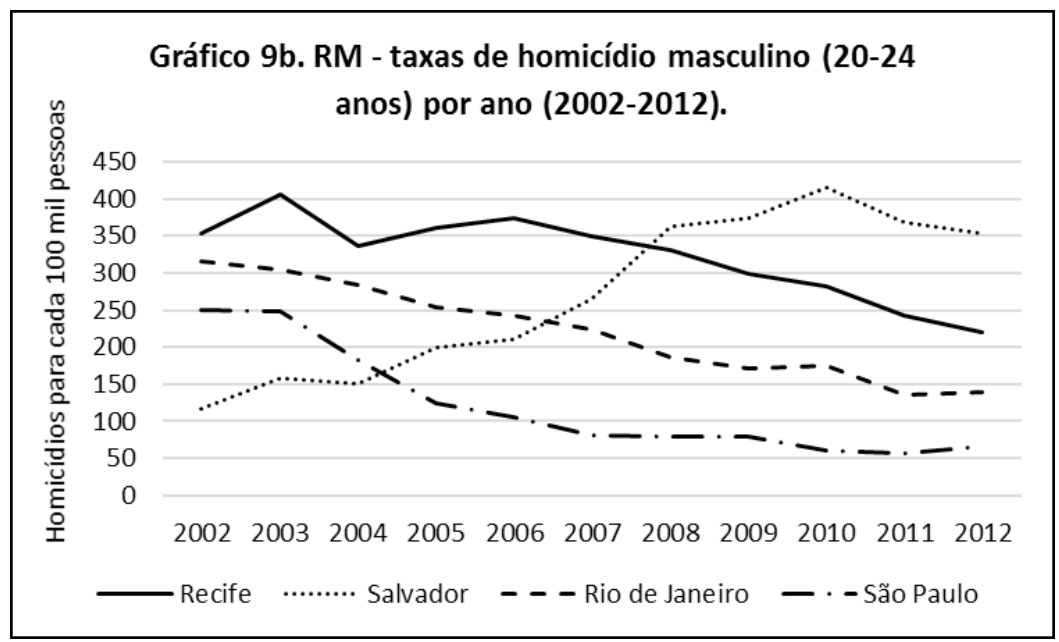

Fonte: elaboração própria com base nos dados do SIM/DATASUS/MS e Projeções da População (2013) - IBGE.

Na RM de São Paulo foram registrados os maiores decréscimos nas taxas de homicídio juvenil masculino dentre as RM observadas, para os dois grupos avaliados. Na sequência os maiores decréscimos foram registrados para as RM do Rio de Janeiro e de Recife. Na RM de Salvador, entretanto, houve um acréscimo evidente, mais intenso para o grupo dos 15-19 do que para o grupo dos 20-24 anos (2002-2012) (Gráfico 10). 


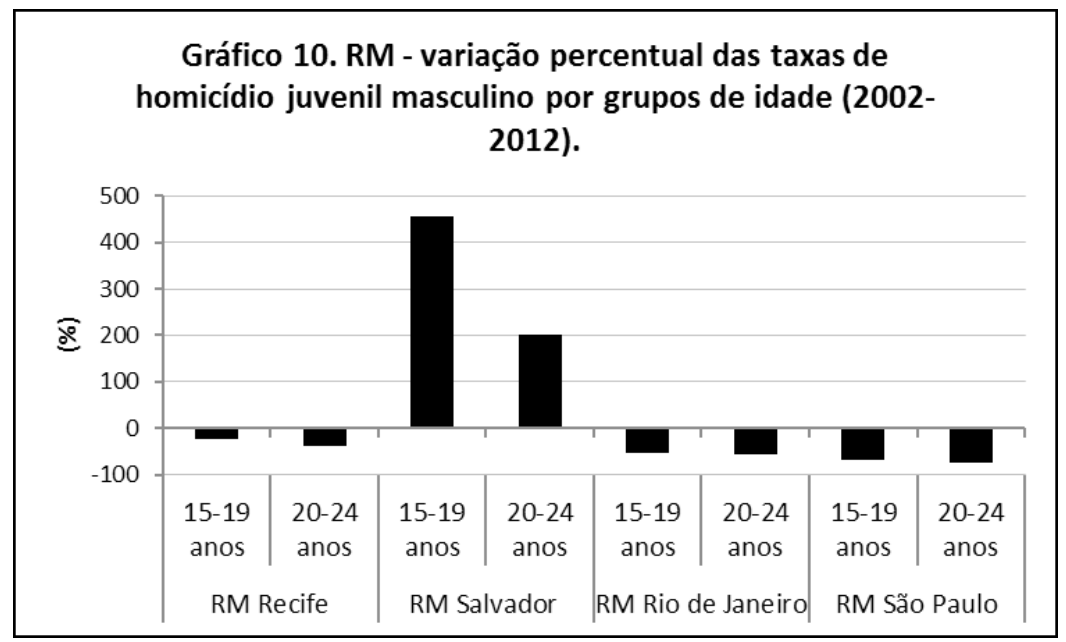

Fonte: elaboração própria com base nos dados do SIM/DATASUS/MS e Projeções da População (2013) - IBGE.

Nas RM de Recife, do Rio de Janeiro e de São Paulo, as taxas de homicídio juvenil masculino declinaram, em acordo com as tendências esperadas com relação ao decréscimo percentual de jovens na população masculina. No entanto, somente nas RM de São Paulo e de Recife a dinâmica de declínio absoluto e proporcional da população jovem foi acompanhada por melhorias nos indicadores de ocupação (2002-2012).

Na RM do Rio de Janeiro o decréscimo da população juvenil não foi acompanhado por melhorias nos indicadores de ocupação, ao contrário. Ademais, o desemprego diminuiu à custa de um aumento significativo da inatividade, em uma situação parecida com aquela observada na RM de Salvador. A diferença principal dos dados observados nessas duas RM é que as taxas de homicídio juvenil masculino diminuíram na RM do Rio de Janeiro e aumentaram na RM de Salvador. Essa diferença pode ser o resultado de distintas capacidades de absorção da população juvenil em sistemas públicos e particulares de ensino formal, além de outras oportunidades de inserção social, quando muito mais 
jovens economicamente inativos poderiam estar estudando na RM do Rio de Janeiro do que na RM de Salvador.

\section{2 - Discussão}

Os resultados obtidos revelam que a dinâmica demográfica recente (2002-2012), caracterizada pela diminuição absoluta e proporcional da população jovem masculina, não tem sido necessariamente acompanhada por melhorias nas condições de ocupação laboral nas RM avaliadas. Da mesma forma, as taxas de homicídio juvenil masculino não apresentaram um decréscimo generalizado, como seria de se esperar segundo a perspectiva da onda jovem (ver Item 1 ).

A grande exceção é representada pela RM de Salvador, onde a diminuição absoluta e proporcional da população jovem masculina foi acompanhada tanto por uma diminuição das taxas de ocupação quanto por um aumento nas taxas de inatividade e por um intenso aumento nas taxas de homicídio. Salientam-se tendências diferenciais das dinâmicas social e demográfica entre as quatro RM avaliadas, fato que sugere a heterogeneidade desses processos e fenômenos segundo diferentes contextos (2002-2012).

Uma avaliação mais ampla do tema proposto revela que outros fatores, além da dinâmica demográfica e da evolução das condições de ocupação laboral, devem ser considerados nos processos de elevação/declínio das taxas de homicídio entre homens jovens em RM brasileiras, com destaque para processos como: a elevação das taxas de matrícula escolar e a tendência de diminuição do trabalho infanto-juvenil, as alterações no número de vagas de trabalho disponibilizadas, as campanhas de desarmamento e as políticas de segurança pública e de repressão ao crime.

Considerando exclusivamente as políticas de repressão ao crime, Sachsida e Mendonça (2014) avaliaram que a mesma estratégia tende a representar efeitos distintos sobre as taxas de homicídio em contextos particulares, fato que levou ao seguinte questionamento: o que funciona em São Paulo pode funcionar também na Bahia? 
Da mesma maneira, outros fatores podem variar significativamente seu peso nas condições de ocupação laboral e nas tendências de elevação/decréscimo da violência juvenil homicida, segundo contextos sociais e demográficos diferenciados, de modo que se torna conveniente ponderar as influências de cada variável em situações específicas.

Muniz (2002), por exemplo, destaca a variabilidade representada pela evolução do mercado de trabalho em cada uma das RM brasileiras, independentemente da pressão demográfica exercida, de modo que as condições de ocupação laboral, para uma população qualquer, podem variar a partir da ocorrência de períodos de recessão ou de bonança econômica.

É necessário advertir que, embora reafirmada a significância dos indicadores socioeconômicos com relação à ocorrência de elevadas taxas de homicídio, essa é uma associação que não pode ser compreendida de forma unívoca ou linear (MINAYO, 2005), já que a despeito dos avanços ${ }^{6}$ sociais recentemente observados no Brasil (IBGE, 2013), as taxas de homicídio continuam se elevando em nível nacional.

\section{3 - CONCLUSÕES}

Conclui-se que a explicação demográfica para a elevação das taxas de homicídio juvenil masculino não se aplica ao conjunto de RM avaliadas, ainda que se mostre relevante nos casos particulares das RM de São Paulo e de Recife. Os resultados revelam que a dinâmica caracterizada pela diminuição absoluta e proporcional da população jovem não tem sido necessariamente acompanhada por melhorias nas condições de ocupação, desemprego e inatividade, nem tampouco por uma diminuição das taxas de homicídio, como era de se esperar segundo a perspectiva da onda jovem.

A partir desses resultados reconhece-se que a retração do volume da população juvenil masculina só será convertida em

\footnotetext{
${ }^{6}$ Referência a avanços como a elevação da renda média per capita e da escolaridade, a redução do desemprego, da pobreza e da desigualdade.
} 
melhores indicadores de ocupação e em uma menor pressão no contexto da competição entre indivíduos e, consequentemente, em menores taxas de homicídio, caso o mercado de trabalho apresente expansão ou ao menos estabilidade do número de vagas disponibilizadas. Desse modo, a equação esperada entre dinâmica demográfica, mercado de trabalho e melhorias nas condições de sobrevivência entre homens jovens não seria possível em todo e qualquer contexto social e econômico.

Perante o exposto, considera-se que além da dinâmica demográfica, da evolução das condições de ocupação e da variabilidade das vagas disponibilizadas pelo mercado laboral, outras variáveis, como a taxa de matrícula escolar, por exemplo, devem ser incluídas em suas relações com os processos de alterações nas taxas de desemprego e de inatividade e, consequentemente, com a tendência de alterações das taxas ocupação laboral e de homicídio.

Esse é um problema que deve ser analisado a partir de perspectivas atualizadas e complexas, avaliando-se as interrelações entre mais diversos fatores e a variabilidade intrínseca de seus respectivos pesos em contextos sociais e econômicos específicos. Dessa maneira, conclui-se que a possibilidade de uma futura redução nas taxas de homicídio não está diretamente relacionada às tendências da dinâmica demográfica, como se fosse uma simples questão de tempo, já que a proporção e o volume absoluto de homens jovens tendem a diminuir durante as seguintes décadas no Brasil, tanto em nível nacional como em todas as RM brasileiras. 


\section{Referências}

ADORNO, Sérgio. Exclusão socioeconômica e violência urbana. Sociologias, v. 4, n. 8, p. 84-135, 2002.

AIDAR, Tirza. A face perversa da cidade: configuração sócioespacial das mortes violentas em Campinas nos anos 90. Tese (Doutorado). Universidade Estadual de Campinas, Instituto de Filosofia e Ciências Humanas, Campinas, 2003.

ARENDT, Hannah (1985). Da violência. Brasília: Editora Universidade de Brasília, 1985.

BERCOVICH, Alicia. Onda jovem, mercado de trabalho e violência: um enfoque demográfico. Tese (Doutorado). Universidade Estadual de Campinas, Instituto de Filosofia e Ciências Humanas, Campinas, 2004.

BERCOVICH, Alicia; DELLASOPPA, Emilio; ARRIAGA, Eduardo. J'ad junte, mais je ne corrige pas: jovens, violência e demografia no Brasil. Algumas reflexões a partir dos indicadores de violência. In: BERQUÓ, Elza (Org.). Jovens acontecendo na trilha das políticas públicas. Brasília: IPEA/CNPD, 1998, p. 293-363.

BERCOVICH, Alicia; MADEIRA, Felícia. Descontinuidades demográficas no Brasil e no Estado de São Paulo. In: Encontro Nacional de Estudos Populacionais, 1., 1990, Caxambu. Anais... Caxambu: ABEP, 1990.

BERCOVICH, Alicia; MASSÉ, Gladys. Descontinuidades demográficas, onda jovem e mercado de trabalho: uma comparação entre Brasil e Argentina. In: Congreso de la Asociación Latinoamericana de Estudios de Población, 1., 2004, Caxambu. Anais... Caxambu: ALAP, 2004.

DOMENACH, Jean M. La violencia. In: Unesco. La violencia y sus causas, Nova York: Editorial de la Unesco, 1981, p 33-46.

EASTERLIN, R. Birth and fortune: the impact of numbers on personal welfare. Chicago: University of Chicago Press, 1980. 
FERREIRA, I. C. B.; VASCONCELOS, A. M. N.; PENNA, N. de A. Violência urbana: a vulnerabilidade dos jovens da periferia das cidades. Encontro Nacional de Estudos Populacionais, 1., 2008, Caxambu. Anais... Caxambu: ABEP, 2008.

GALTUNG, Johan. Cultural violence. Journal of peace research, $v$. 27, n. 3, p. 291-305, 1990.

HIRATA, Helena. Salariado, precariedade, exclusão. Trabalho e relações sociais de sexo-gênero: uma perspectiva internacional. In: OLIVEIRA, M. C. (Org.) Demografia da exclusão social: temas e abordagens. Campinas: Editora da Unicamp/Nepo, 2001, p. 105118.

INSTITUTO BRASILEIRO DE GEOGRAFIA E ESTATÍSTICA. Síntese de Indicadores Sociais. Uma análise das condições de vida da população brasileira. Rio de Janeiro: IBGE, 2013.

LIVI-BACCI, Massimo. 500 anos de demografia brasileira: uma resenha. Revista Brasileira de Estudos de População, v.19, n.1, p. 141-159, 2002.

MANETTA, A.; ALVES, J. E. D. Óbitos violentos e inflexão precoce na razão de sexo: Argentina e Brasil (2001-2011). Revista Latinoamericana de Población, n. 17, p. 83-106, 2015.

MATTA, Roberto da. As raízes da violência no Brasil: reflexões de um antropólogo social. In: MATTA, Roberto da (Org.). Violência brasileira, 1982, p. 14-28.

MERRICK, T. W.; GRAHAM, D. H. População e desenvolvimento econômico no Brasil de $\mathbf{1 8 0 0}$ até a atualidade. Rio de Janeiro: Zahar editores, 1979.

MICHAUD, Yves (1986). La violence. Presses Universitaires de France. Paris (1986).

MINAYO, M. C. de S. Violência um problema para a saúde dos brasileiros. In: Brasil. Ministério da Saúde, Impacto da violência na saúde dos brasileiros. Brasília: Ministério da Saúde, 2005, p. 9-33, 2005. 
MUNIZ, J. O. As descontinuidades demográficas exercem efeitos sobre o mercado de trabalho metropolitano de jovens? Revista Brasileira de Estudos da População, v.19, n.2, p. 65-98, 2002.

OLIVEIRA, M. C.; PINTO, L. G. Exclusão social e demorafia: elementos para uma agenda. In: OLIVEIRA, M. C. (Org.) Demografia da exclusão social: temas e abordagens. Campinas: Editora da Unicamp/Nepo, 2001, 12-58 p.

SACHSIDA, A.; MENDONÇA; M. J. C. de. Combatendo os homicídios no Brasil: o que funciona em São Paulo funciona na Bahia. In: IPEA. Texto para Discussão, Rio de Janeiro: IPEA, $n$. 1979, 2014, p. 11-40.

SOUZA, Edinilsa R. de; LIMA, Maria L. C. de. Panorama da violência urbana no Brasil e suas capitais. Ciência \& Saúde Coletiva, v. 11, 2006.

SWANSON, D.; SIEGEL, J. S. The methods and materials of demography. San Diego: Academic Press, 1976.

VELHO, Gilberto. O desafio da violência. Estudos Avançados, v. 14, n. 39, p. 56-60, 2000.

WAISELFISZ, J. J. Mapa da violência 2014: os jovens do Brasil. Brasília: FLACSO, 2014.

ZALUAR, Alba. Democratização inacabada: fracasso da segurança pública. Estudos Avançados, v. 21, n. 61, p. 31-49, 2007. 